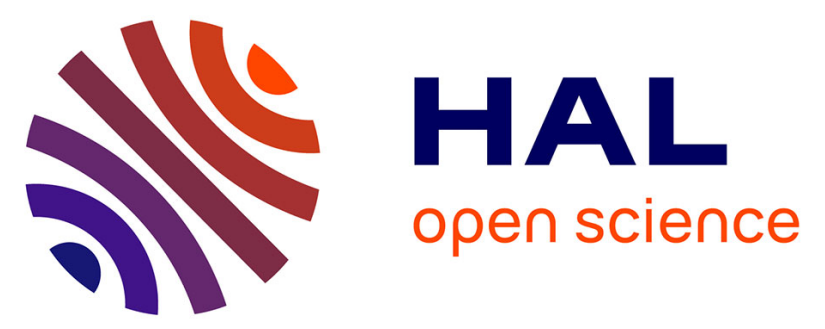

\title{
A comparison of bone union and complication rates between locking and non-locking plates in distal fibular fracture: Retrospective study of 106 cases
}

Bachar El Fatayri, Yassine Bulaïd, Az-Eddine Djebara, Eric Havet, Patrice Mertl, Massinissa Dehl

\section{To cite this version:}

Bachar El Fatayri, Yassine Bulaïd, Az-Eddine Djebara, Eric Havet, Patrice Mertl, et al.. A comparison of bone union and complication rates between locking and non-locking plates in distal fibular fracture: Retrospective study of 106 cases. Injury, 2019, 50, pp.2324 - 2331. 10.1016/j.injury.2019.10.001 . hal-03488445

\section{HAL Id: hal-03488445 \\ https://hal.science/hal-03488445}

Submitted on 21 Dec 2021

HAL is a multi-disciplinary open access archive for the deposit and dissemination of scientific research documents, whether they are published or not. The documents may come from teaching and research institutions in France or abroad, or from public or private research centers.
L'archive ouverte pluridisciplinaire $\mathbf{H A L}$, est destinée au dépôt et à la diffusion de documents scientifiques de niveau recherche, publiés ou non, émanant des établissements d'enseignement et de recherche français ou étrangers, des laboratoires publics ou privés.

\section{(ㅇ)(1) $\$$}

Distributed under a Creative Commons Attribution - NonCommerciall 4.0 International 


\section{A Comparison of Bone Union and Complication Rates for Locking vs. Non-Locking Plates in Distal Fibular Fracture: a Retrospective Study of 106 Cases.}

Bachar EL FATAYRI ${ }_{1}^{*}$; Yassine BULAID 1 ; Az-Eddine DJEBARA 1 ; Eric HAVET 1 ; Patrice MERTL 1 ; Massinissa DEHL 1

(1) - Orthopedic surgery department, CHU Amiens - Picardie, 80480, Salouël, France

*Corresponding author / Email: elfatayri.bachar@gmail.com

Word count: $\mathbf{3 6 5 7}$ 


\title{
A Comparison of Bone Union and Complication Rates between Locking and Non-Locking Plates in Distal Fibular Fracture: Retrospective Study of 106 Cases.
}

\begin{abstract}
$\underline{\text { Abstract: }}$
Background: Ankle fractures represent the third most frequent fracture in elderly patients. There is a current tendency to fix long bones fractures with locking plates. However, we rarely find published accounts about the use of locking plates in distal fibula fractures, except for biomechanical ones, studying human cadaveric fibula.
\end{abstract}

Objectives: The main objective was to compare radiographic bone union rates at 6 and 12 weeks of follow up, then wound complications and hardware removal rates, and construct cost.

Study Design \& Methods: We retrospectively analyzed 105 patients who underwent surgery with locking plates or non-locking plates over a two-year period, out of which 42 patients were treated with non-locking plates (VIVES ${ }^{\mathrm{TM}}$ - Stryker ${ }^{\mathbb{B}}$ ) and 63 with locking plates $\left(\right.$ VariAx $^{\mathrm{TM}}$ - Stryker ${ }^{\circledR}$,). We analyzed bone union on anterior posterior and lateral Xrays of the ankle. We collected data of wound complications and hardware removal from patient records. Multiple linear regression techniques were performed after identifying dependent variables.

Results: There was no significant difference between non-locking and locking plates in the radiographic bone union rate of distal fibula, respectively at 6 and 12 post-operative weeks ( $85.71 \%$ vs. $81 \% ; p=0.525$ and $97.62 \%$ vs. $96.83 \% ; p=1)$. No significant difference was found in the wound complication rate between the two groups $(11.9 \%$ vs. $11.12 \% ; p=0.9)$. No significant differences were found in the hardware removal rate, either with or without operative site's infection (respectively: $30.95 \%$ vs. $39.68 \%$; $=0.361$ and $21.42 \%$ vs. $38.09 \% ; \mathrm{p}=0.071)$. Cost efficiency is in the favor of non-locking plates.

Conclusion: Non-locking constructs are as effective as locking constructs in the treatment of displaced distal fibula fractures at a substantially lower cost. High-quality randomized controlled trials are needed in the future to verify the finding of this study.

Keywords: Ankle Fracture, Distal Fibula, Locking Plate, Bone Union 


\section{INTRODUCTION :}

Ankle fractures are frequent in traumatology. Their incidence of 122 to 184 per 100,000 people/year (1-3), out of witch $25 \%$ in elderly over 65 (4), puts them as the third most common fracture in elderly patients $(3,5)$. Open reduction and internal fixation in displaced distal fibula fractures is considered as the treatment of choice (6). The most common surgical technique nowadays is plating (7). The advent of locking-plates has radically changed the management of long bones fractures (8-11). This innovation using fixed-angle screws offers better angular and axial stability $(12,13)$, particularly in metaphysis and epiphysis, independently of bone mineral density (12). These Locking constructs have progressively changed our surgical practices, especially in cases of osteoporosis or comminuted fractures, instability and/or cortical fixation difficulties (13).

Several cadaveric studies biomechanically comparing locking plates (LP) and non-locking plates (NLP) have been conducted (14-20). However, few studies compared bone union in distal fibula fractures treated with Locking vs. non-locking constructs (21-24).

The primary outcome of our study was to assess radiographic bone union rates in distal fibula fractures of a NLP (VIVES ${ }^{\mathrm{TM}}$, Stryker ${ }^{\circledR}$, Mahwah, NJ, USA) vs. a LP $\left(\right.$ VariAx $^{\mathrm{TM}}$, Stryker $^{\circledR}$, Mahwah, NJ, USA) at 6 and 12 weeks of follow up. Secondary outcomes included the assessment of wound complications and hardware removal rates, in addition to a comparison of each construct's cost. Our key assumption was that Non-locking constructs are as effective as locking constructs in the treatment of displaced distal fibula fractures.

\section{PATIENTS and METHODS :}

\section{Population:}

We retrospectively reviewed a consecutive cohort of patients who underwent surgical fixation of closed malleolar fractures of the ankle between January 2012 and December 2013. We included patients above 18, with displaced isolated distal fibula, bi malleolar or tri malleolar fractures, treated surgically with either a LP or NLP, with a minimal 3 months follow-up period. Open ankle fractures, pilon or diaphyseal associated fractures and injuries treated with another type of osteosynthesis (isolated medial malleolar fracture treated with screws, fractures treated with external fixators, fractures treated with krischner wires, fractures treated with isolated syndesmotic screws) were excluded. After excluding non-eligible patients, we 
have sent a memorandum notifying concerned patients about their participation. The memo defines the purpose of the study and its execution, in addition to their right of objection and withdrawal regarding the use of their personal information (25).

Data was collected from patient charts and electronic records of the department of orthopedic surgery and traumatology of our institution. The fracture type was defined on preoperative anterior-posterior and lateral radiographs according to AO classification (26). The primary outcome was the radiographic confirmation of lateral malleolar fracture union at 6 and 12 weeks. We defined radiographic union as the disappearance of all fracture lines in the anterior posterior and lateral views. Two senior orthopedic surgeons, blinded to the aim and protocol of the study, determined separately the radiographic union of each case. In the event of disagreement, a third interpretation was performed by an independent radiologist to decide this issue. Wound complications were split into superficial or minor complications (delayed wound healing and wound secondary dehiscence) and deep or major infectious complications (27). Clinical outcomes as pain, swelling and stiffness, as well as hardware removal percentage were recorded from follow-up data. The construct costs were calculated using the prices of the sales made by the corresponding trader to our institute.

\section{Operative technique :}

All procedures were performed in a supine position under general or spinal anesthesia. All patients benefited from the use of a tourniquet at top of thigh and received antibiotic prophylaxis according to the institute protocol. After fracture reduction, the use of lag screws as well as the plate's thickness was left to the discretion of the operation surgeon. Then a locking or non-locking plate was placed on the lateral aspect of the fibula. Surgeons had no choice in the type of plate they would use: In 2012, there was only NLP available in our institute and as of January 2013, they were replaced with LP. The NLP used, Vives ${ }^{\mathrm{TM}}$ (Stryker ${ }^{\circledR}$, Mahwah, NJ, USA) was a MACONOR-2 type periarticular plate characterized by its "diamond-shaped" rough deep surface and its continuous $1.8 \mathrm{~mm}$ thickness. The LP, VariAx ${ }^{\mathrm{TM}}$ fibula locking plate system (Stryker ${ }^{\circledR}$, Mahwah, NJ, USA), is a low profile precountered periarticular plate. It is $2 \mathrm{~mm}$ thick proximally and $1.3 \mathrm{~mm}$ distally, and it possesses the SmartLock ${ }^{\mathrm{TM}}$ polyaxial locking mechanism (Figure 1). All proximal plate screws were non-Locking in both groups. All four distal plate screws were cancellous non-Locking in the NLP group and Locking in the LP group (Figures 2 and 3). Medial malleolar fractures were reduced and fixed with either cancellous screws or tension band wiring. Anterior posterior 
screws were eventually used in case of a displaced posterior fragment. Medial collateral ligament suture and or syndesmotic repairing by a temporary screw have been undertaken when necessary. Drains were routinely used and wound closure techniques were common to both groups. All patients benefited from a plaster cast postoperatively and a pharmacological venous thromboembolic prophylaxis throughout 6 weeks of immobilization and non-weight bearing. Clinical and radiographic follow-up was routinely achieved at 3,6 and 12 weeks postoperatively. Weight-bearing and rehabilitation began after 6 weeks. Further follow-up examinations were established in case of complication.

\section{Statistical analysis :}

Statistical analysis was performed using «R-Studio®» version 3.4.2 for Windows ${ }^{\circledR}$ (Boston, USA). Descriptive statistics were performed to summarize demographic and clinical variables and to evaluate distributional characteristics. Continuous variables were evaluated using Student and Wilcoxon tests, and were expressed with means $+/$ - standard deviation and range. Categorical data were evaluated using Chi-square or Fisher tests, and expresses as percentages. We used simple linear analysis studying the direct relation between the variable and the primary outcome. Multiple linear regression techniques were performed after identifying dependent variables. Data was expressed as odds ratios with their ninety-five percent confidence intervals and p-values defined at 5\% (statistical significance was defined at $\mathrm{p}<0,05)$.

\section{RESULTS}

A total of 198 ankle fractures were assessed between January 2012 and December 2013. After applying exclusion criteria, there was left 128 distal fibulas that underwent fixation with a lateral plate. Twenty-two patients were lost during follow-up. After inclusion, one patient expressed his opposition to the use of his personal data by a written letter. A hundred and five patients were analyzed: 42 received a NLP and 63 received a LP (Figure 4). 


\section{Population and surgical characteristics}

The mean age of the population at surgery was fifty years $[17 ; 84]$ and $60 \%$ of patients were female. Mean body mass index (BMI) was $26,7 \mathrm{Kg} / \mathrm{m}^{2}[16.4 ; 46.2]$. The most frequent comorbidity was smoking $(n=44 ; 41.9 \%)$. We have found 31 dislocated ankles $(29.52 \%)$ and the rate of skin blisters, before and after surgery, was 14, 29\%. Referring to the AO classification for ankle fractures, type 44-B was predominant $(\mathrm{n}=102.97,14 \%)$ and sub-type 44-B2 or bi-malleolar was the most frequent $-n=70 ; 66.67 \%$ ). All the population's data is detailed in table 1 . No significant differences were found between groups in all variables except for the AO fracture type $(\mathrm{p}=0.011)$ and sub-type 44-B $(\mathrm{p}=0.024)$. The use of lag screws in conjunction with the plate was significantly higher in the NLP group $(65.08 \%$ vs. $40.48 \% ; \mathrm{p}=0.012)$.

\section{Radiographic bone union rate}

Bone union rate is detailed in table 2. We have not found a significant difference in bone union rate either at 6 or 12 weeks postoperatively between NLP and LP groups. Simple linear analysis of bone union at 6 and 12 weeks are exposed in table 3. Odds ratios concerning multiple linear regression analysis at 6 weeks are exposed in table 4. Multivariable analysis has not found any differences in bone union at 6 weeks after adjustment for age, gender and fracture type. However, a significant difference was found in both groups, with sub-type 44B3 requiring longer time to bone union comparing to sub-type-B2 $(\mathrm{OR}=0.25$ [0.069-0.936]; $\mathrm{p}=0.035$ ). Concerning bone union at 12 weeks, multiple linear regression analysis have showed a statistically significant delay in bone union in case of skin blisters $(\mathrm{OR}=0.066$ [0.003; 0.762]; 0.034). Other variables were not related to bone union delay. Odds ratios concerning multiple linear regression analysis at 12 weeks are exposed in table 5.

\section{Complications}

Complication rates are detailed in table 6. Twelve wound complications were found the cohort, including four deep infections in NLP group and two in LP group. There was no significant difference in wound complications in the NLP group compared to the LP group (11.9 vs. $11.1 ; \mathrm{p}=0.9$ ). This finding was similar when comparing minor and major wound complications between the study groups (respectively: 2.38 vs. $7.94 ; p=0.398$ and 9.52 vs. 3.17; $\mathrm{p}=0.154)$. The rates of other complications were comparable $(\mathrm{p}=0.138)$. There were no early revisions, except for syndesmotic screws ablation at 6 postoperative weeks. One patient 
required a late arthroscopic arthrolysis in the context of ankle equinus stiffness. Multiple linear regression techniques could not be performed for complication rates.

\section{Hardware removal (HR)}

The overall HR rate was $36.19 \%$ (table 7) and there was no significant difference between the groups $(p=0.361)$. All four infected sites of the NLP group have benefited of HR. On the contrary, in the LP group, only one out of two plates was removed after infection. The plate left in place was of an early infection while the fracture had not healed yet. After taking HR for infection out of count, there was 9 HR $(21.42 \%)$ in the NLP group and 24 HR (38.09\%) in the LP group. This difference was not statistically significant $(\mathrm{p}=0.071)$. Plate removal was performed earlier in the NLP group independently of the infection factor (respectively: 13.5 +/- 2.5 vs. $17.2+/-7.7 ; \mathrm{p}=0.044 ; 10.2+/-5.43$ vs. $16.5+/-8.1 ; \mathrm{p}=0.007)$. Simple linear analyses of hardware removal are illustrated in table 3. The influential variables were age, fracture sub-type 44-B and wound complications. A multiple linear regression analysis concerning these variables has been performed as can be seen in table 8. It has been demonstrated that $\mathrm{HR}$ rates decreases with age $(\mathrm{OR}=0,94$ [0.899; 0.978]; $\mathrm{p}=0.004)$. Otherwise, it was observed that fracture sub-type 44-B3 causes 4 times as many hardware removals as sub-type 44-B2 and 8.5 times as many as sub-type 44-B1. These results were statistically significant (respectively: $\mathrm{OR}=4.075$ [1.021; 17.455]; $\mathrm{p}=0.048$ and $\mathrm{OR}=8.568$ [1.478; 59.817]; $\mathrm{p}=0.021)$. In contrast, there was no difference between sub-types 44-B1 and 44-B2.

\section{Constructs costs}

Table 9 shows the price of each plate and different type of screws. Since they have the same price, proximal bicortical screws were not taken into account. It has been noted that a locking construct is 235.5 euros more expensive than a standard non locking construct.

\section{IV- Discussion}

When a closed and displaced distal fibula fractures occurs, it is essential to regain the length of the fibula and maintain the stability of the ankle joint. Surgical treatment is a standard practice in the young and active population which demands a quick return to their activities. In elderly patients (over 60) with unstable ankle fractures, a recent randomized clinical trial with blinded outcome assessors have showed that the use of close contact casting compared 
with surgery resulted in similar functional outcomes (28). A substantial increase in the use of countered locking plates occurred in treating distal fibula fractures at our institution, whatever the age. The aim of our study was to verify the need to support such a shift in our practices. The primary outcome of our study was to assess radiographic bone union rates in distal fibula fractures of a NLP (VIVESTM ${ }^{\mathrm{TM}}$ Stryker ${ }^{\circledR}$, Mahwah, NJ, USA) vs. a LP $\left(\right.$ VariAx $^{\mathrm{TM}}$ Stryker $^{\circledR}$, Mahwah, NJ, USA) at 6 and 12 weeks of follow up. It has been shown that the initial assumption is confirmed since there were no difference in bone union rate either at 6 or 12 weeks postoperatively between NLP and LP groups.

Herrera-Pérez \& al. have retrospectively compared locking versus non-locking one-third tubular plates for treating osteoporotic distal fibula fractures. No statistically significant difference in time to radiographic bony union was reported between the two groups (average time of 15.27 weeks [11-16] in LP group vs. 12.58 weeks [9-13] in NLP group $-p=0.15$ ) (22).

Likewise, while retrospectively reviewing a consecutive cohort of 145 patients, Lyle \& al. have not detected significant differences in the radiographic time to bony union among three plate groups including one locked plate (23). In another accessor blinded randomized controlled trial conducted on fifty-two patients to compare the effectiveness of LP and NLP, the intention to treat analyses of Tsukada $\&$ al. showed no difference in the radiographic bone union rate of the fibula (24).

In contrast, in a retrospective cohort of 147 patients, Huang \& al. (21) have compared radiographic outcome of three types of plates. They have found that the healing time was significantly less in patients treated with a LCP distal fibula plate $(20.0 \pm 3.8$ weeks $)$ then in patients treated with a LCP metaphyseal plate $(23.0 \pm 3.4$ weeks, $\mathrm{p}<0.0001)$ and a conventional one-third tubular plate $(23.1 \pm 3.6$ weeks, $\mathrm{p}<0.0001)$. Otherwise, no significant difference was found between the last two plates ( $\mathrm{p}=0.867)$, although one is a locking plate. Interestingly, there is no information of the use of lag screws, which could explain the increase of time to healing in NLP group. In addition, the MIPO technique as described by Hess \& al. (29) was used in the LP groups, which could have theoretically reduced the risk of periosteum damage and the loss of the fracture's hematoma.

On the one hand, some authors have reported the possibility of fixing distal fibula fractures with isolated anterior posterior lag screws, associated with a 6-weeks immobilization period, and ended up having the same results functionally and radiographically $(7,30)$. On the other, 
Takemoto \& al. have demonstrated that both NLP and LP act similarly as a neutralization device when a lag screw is used to implement compression in the fracture site (31). Other cadaveric studies have been carried in the purpose of comparing conventional NLP and new LP biomechanics. No biomechanical differences have been demonstrated when comparing locking and non-locking one-third tubular plates in Weber (32) B and C distal fibula fractures $(14,15,17)$ However, Bariteau \& al. have found that locked plating is biomechanically superior, with a statistically significant stiffer fixation, to a standard one third tubular plate in comminuted Weber $\mathrm{C}$ ankle fractures (17). This finding is lost and both constructs are comparable when fractures are initially fixed with lag screws. It has been demonstrated that fixation with standard NLP is depending on bone mineral density (BMD) whereas the LP was independent of BMD $(14,18)$. Distal periarticular countered plates have been proved biomechanically superior either it is non-locking in the study of Davis \& al. (16) or locking in those of Zahn and Switaj $(18,19)$. These recent biomechanical studies seems to have shown that locking countered plates provides improved fixation strength in osteporotic bone and comminuted distal fibula fractures. Nguyentat et al. concluded to the absence of significant differences between LP and NLP during both fatigue and torque to failure testing in distal fibula fractures with no comminution and normal BMD (20).

The multivariable analysis of this study has found a statistically significant longer time to bone union in sub-type 44-B3 comparing to sub-type-B2 at 6 weeks postoperatively, independently of age, gender and construct type (locking or non-locking). Concerning bone union at 12 weeks, multiple linear regression analysis has showed a statistically significant delay in bone union in case of initial or secondary skin blisters. These findings are in line with those reported by Bhadra \& al. in their meta-analysis about delayed union and nonunion of the fibula between 1950 and 2011. They found that initial fracture pattern, severity of comminution at the fracture site, degree of displacement of fracture fragments, and highenergy injury seemed to be related to the occurrence of delayed fibular union or frank nonunion (33). The distal third of the fibula was the most common site (85\%) for delayed union or pseudoarthrosis in both combined tibia-fibula fractures and low-energy ankle fractures.

The overall wound complication rate for the study $(11.42 \%)$ was comparable to those described in the literature $(22,23,27,34,35)$. There was no significant difference in wound complication rates in the NLP group compared to the LP group (11.9 vs. 11.1; $\mathrm{p}=0.9$ ). Despite the fact that a majority of authors haven't demonstrated any differences in 
complication rates, particularly wound complications, between Locking and non-Locking plates in the fixation of the distal third of the fibula $(22-24,34,36)$, Scheppers (27) and Lynde (35) have found a significant higher wound complication rate in Locking plates. In addition, Moss \& al. reached to a statistically higher percentage of deep infectious complication in the LP group (37).

Scheppers \& al. have compared one-third tubular low profile 1mm thick NLP to High profile $2.8 \mathrm{~mm}$ and $3.3 \mathrm{~mm}$ thick LP. They have concluded to the augmentation of wound complication rates along with the thickness of the used plate (27). The Same conclusion was suggested in Moss's study, where they used LP had 1.7 and $2.8 \mathrm{~mm}$ thick , compared to onethird tubular $1 \mathrm{~mm}$ thick NLP (37). However, Moriarty \& al. have recently demonstrated that the use of locking plates for the treatment of distal fibular fractures is not associated with an increased wound complication rate. They have used low profile periarticular LP $1.3 \mathrm{~mm}$ thick distally, compared to one-third tubular and reconstruction NLP, respectively 1 and $3.5 \mathrm{~mm}$ thick (36).

Moss \& al. have found a HR rate statistically higher in the thicker LP group (37). Schepers \& al. (27) reported a HR rate of $27.3 \%$ without any difference between NLP and thicker LP groups. Contrarily to the findings of our study, the latter also found that plate removal was performed 2 months earlier in the thicker LP group, without this result being statistically significant. Petruccelli \& al. (34) haven't found any difference in HR rates between Locking and non-Locking constructs. Naumann \& al. retrospectively reviewed a cohort of 997 patients in the purpose of determining the risk factors for hardware removal of an internal fixation following ankle fracture surgery (lateral plate and medial / anterior-posterior screws in case of a bi malleolar or tri malleolar fracture). They have revealed that male sex, age and treatment with a syndesmosis screw were associated with a lower hazard for the removal of hardware due to complaints (38). Inversely, an increase in duration of the initial operation was associated with a higher hazard of experiencing hardware removal. Our study has likewise demonstrated that HR rates decreases with age. We have also observed an increase in HR rates in sub-type 44-B3 or trans-syndesmotic tri malleolar fractures. This may be related to functional limitations, discomfort and pain linked to additional implants, particularly screws fixing medial and posterior malleoli. These results should be considered as assumptions for we need further controlled trials to ensure the reliability of such findings, especially since there was no difference between sub-types 44-B1 and 44-B2 in our statistical analyses. 
It is clear that a low profile construct, whether it's Locking or non-Locking, induce a lower incidence of metal prominence, hence less wound complications and HR rates. In this study, the LP is a low profile pre-countered periarticular plate with a distal thickness of $1.3 \mathrm{~mm}$, which is considerably thinner than other LP used in the mentioned studies, and slightly thinner than the periarticular NLP with a distal thickness of $1.8 \mathrm{~mm}$. This could explain the similar outcomes in both wound complications and HR rates between locking and nonlocking constructs in our study.

Financially wise, a typical countered locking plate construct costs $\$ 800$ more than a comparable one-third tubular plate construct in the USA. Based on a calculated estimate of 60000 locking plates used annually, Moss \& al. have found that a total of $\$ 50$ million can be avoided annually (37). Our study has equally found a staggering higher price for the locking construct which is 235.5 euros more expensive than a standard non locking construct. We can easily save millions of euros on a French national scale by using non-locking constructs for non-comminuted distal fibula fractures with normal BMD.

Finally, the present retrospective study has limitations. The patients were not randomized for treatment with the two types of fixations. However the choice of the period of the study is linked to the fact that we have always used NLP for distal fibula fractures, until the end of 2012 when our department started using the LP. This was in the purpose of decreasing selection bias! The overall number of patients was relatively small. No significant differences were found between groups in all variables except for the AO fracture type. Sub-types A and $\mathrm{C}$ couldn't be integrated in a multiple linear regression analysis because of their small numbers. Sub-type B had to be analyzed alone, which generated a selection bias. The use of lag screws in conjunction with the plate was not comparable between groups, which constituted a confounding factor. Further studies with improved design to account for these different biases are needed. 


\section{V- Conclusion:}

Locking plates are increasingly used for fractures of distal fibula and are associated with significantly augmented costs. Bone union rates appear to be similar in both locking and nonlocking constructs of the distal fibula, especially in case of an associated immobilization. Locking plates are an interesting option in comminuted and/or osteoporotic fractures. The thickness of the plate appears to be correlated to the onset of wound complications. Measures to increase surgeons' awareness about cost-reduction programs are needed. High-quality randomized controlled trials are needed in the future to verify the finding of this study.

\section{VI - Conflict of interest}

The authors declare no conflict of interest. This research did not receive any specific funding from organizations in the public, commercial, or not-for-profit sectors.

TEXT WORD COUNT: 3657 (without abstract and references) 


\section{VI - References}

1. Donken CCMA, Al-Khateeb H, Verhofstad MHJ, van Laarhoven CJHM. Surgical versus conservative interventions for treating ankle fractures in adults. Cochrane Database Syst Rev. 15 août 2012;(8):CD008470.

2. Crevoisier X, Baalbaki R, Dos Santos T, Assal M. Ankle fractures in the elderly patient. Rev Med Suisse. 17 déc 2014;10(455):2420-3.

3. Bariteau JT, Hsu RY, Mor V, Lee Y, Digiovanni CW, Hayda R. Operative Versus Nonoperative Treatment of Geriatric Ankle Fractures: A Medicare Part A Claims Database Analysis. Foot and ankle international. 2015;36(6):648-55.

4. Willett K, Keene DJ, Mistry D, Nam J, Tutton E, Handley R, et al. Close Contact Casting vs Surgery for Initial Treatment of Unstable Ankle Fractures in Older Adults: A Randomized Clinical Trial. JAMA. 11 oct 2016;316(14):1455-63.

5. Court-Brown CM, McBirnie J, Wilson G. Adult ankle fractures--an increasing problem? Acta Orthop Scand. févr 1998;69(1):43-7.

6. Ali MS, McLaren CA, Rouholamin E, O'Connor BT. Ankle fractures in the elderly: nonoperative or operative treatment. J Orthop Trauma. 1987;1(4):275-80.

7. McKenna P, O’Shea K, Burke T. Less is more:lag screw only fixation of lateral malleolar fractures. International Orthopaedics. 1 août 2007;31(4):497-502.

8. Perren SM. Evolution of the internal fixation of long bone fractures. The scientific basis of biological internal fixation: choosing a new balance between stability and biology. $\mathrm{J}$ Bone Joint Surg Br. nov 2002;84(8):1093-110.

9. Wagner M. General principles for the clinical use of the LCP. Injury. nov 2003;34 Suppl 2:B31-42.

10. Haidukewych GJ, Ricci W. Locked plating in orthopaedic trauma: a clinical update. J Am Acad Orthop Surg. juin 2008;16(6):347-55.

11. Anglen J, Kyle R, Marsh J, Virkus W, Watters W, Keith M, et al. Locking Plates for Extremity Fractures. Journal of the American Academy of Orthopaedic Surgeons. 1 juill 2009;17(7):465-72. 
12. Miranda MA. Locking plate technology and its role in osteoporotic fractures. Injury. sept 2007;38 Suppl 3:S35-39.

13. Jastifer JR. Topical review: locking plate technology in foot and ankle surgery. Foot Ankle Int. mai 2014;35(5):512-8.

14. Kim T, Ayturk UM, Haskell A, Miclau T, Puttlitz CM. Fixation of osteoporotic distal fibula fractures: A biomechanical comparison of locking versus conventional plates. J Foot Ankle Surg. 2007;46(1):2-6.

15. White NJ, Corr DT, Wagg JP, Lorincz C, Buckley RE. Locked plate fixation of the comminuted distal fibula: a biomechanical study. Can J Surg. févr 2013;56(1):35-40.

16. Davis AT, Israel H, Cannada LK, Bledsoe JG. A biomechanical comparison of one-third tubular plates versus periarticular plates for fixation of osteoporotic distal fibula fractures. J Orthop Trauma. sept 2013;27(9):e201-207.

17. Bariteau JT, Fantry A, Blankenhorn B, Lareau C, Paller D, Digiovanni CW. A biomechanical evaluation of locked plating for distal fibula fractures in an osteoporotic sawbone model. Foot Ankle Surg. mars 2014;20(1):44-7.

18. Zahn RK, Frey S, Jakubietz RG, Jakubietz MG, Doht S, Schneider P, et al. A contoured locking plate for distal fibular fractures in osteoporotic bone: a biomechanical cadaver study. Injury. juin 2012;43(6):718-25.

19. Switaj PJ, Wetzel RJ, Jain NP, Weatherford BM, Ren Y, Zhang L-Q, et al. Comparison of modern locked plating and antiglide plating for fixation of osteoporotic distal fibular fractures. Foot Ankle Surg. sept 2016;22(3):158-63.

20. Nguyentat A, Camisa W, Patel S, Lagaay P. A Biomechanical Comparison of Locking Versus Conventional Plate Fixation for Distal Fibula Fractures in Trimalleolar Ankle Injuries. J Foot Ankle Surg. févr 2016;55(1):132-5.

21. Huang Z, Liu L, Tu C, Zhang H, Fang Y, Yang T, et al. Comparison of three plate system for lateral malleolar fixation. BMC Musculoskelet Disord. 30 oct 2014;15:360.

22. Herrera-Pérez M, Gutiérrez-Morales MJ, Guerra-Ferraz A, Pais-Brito JL, BoludaMengod J, Garcés GL. Locking versus non-locking one-third tubular plates for treating osteoporotic distal fibula fractures: a comparative study. Injury. nov 2017;48 Suppl 6:S60-5.

23. Lyle SA, Malik C, Oddy MJ. Comparison of Locking Versus Nonlocking Plates for Distal Fibula Fractures. J Foot Ankle Surg. août 2018;57(4):664-7.

24. Tsukada S, Otsuji M, Shiozaki A, Yamamoto A, Komatsu S, Yoshimura H, et al. Locking versus non-locking neutralization plates for treatment of lateral malleolar fractures: a randomized controlled trial. Int Orthop. déc 2013;37(12):2451-6.

25. Laigneau J-F. Sécurité des patients et développement des recherches : de la loi Bertrand à la loi Jardé. Médecine \& Droit. 1 nov 2012;2012(117):163-9. 
26. Meling T, Harboe K, Enoksen CH, Aarflot M, Arthursson AJ, Søreide K. How reliable and accurate is the AO/OTA comprehensive classification for adult long-bone fractures? J Trauma Acute Care Surg. juill 2012;73(1):224-31.

27. Schepers T, Van Lieshout EMM, De Vries MR, Van der Elst M. Increased rates of wound complications with locking plates in distal fibular fractures. Injury. oct 2011;42(10):1125-9.

28. Wetzel RJ, Kempton LB, Lee ES, Zlowodzki M, McKinley TO, Virkus WW. Wide Variation of Surgical Cost in the Treatment of Periarticular Lower Extremity Injuries Between 6 Fellowship-Trained Trauma Surgeons. J Orthop Trauma. déc 2016;30(12):e377-83.

29. Hess F, Sommer C. Minimally invasive plate osteosynthesis of the distal fibula with the locking compression plate: first experience of 20 cases. J Orthop Trauma. févr 2011;25(2):110-5.

30. Tornetta P, Creevy W. Lag screw only fixation of the lateral malleolus. J Orthop Trauma. févr 2001;15(2):119-21.

31. Takemoto RC, Sugi MT, Kummer F, Koval KJ, Egol KA. The effects of locked and unlocked neutralization plates on load bearing of fractures fixed with a lag screw. J Orthop Trauma. sept 2012;26(9):519-22.

32. Kennedy JG, Johnson SM, Collins AL, Dallovedova P, McManus WF, Hynes DM, et al. An evaluation of the Weber classification of ankle fractures. Injury. 1 oct 1998;29(8):577-80.

33. Bhadra AK, Roberts CS, Giannoudis PV. Nonunion of fibula: a systematic review. Int Orthop. sept 2012;36(9):1757-65.

34. Petruccelli R, Bisaccia M, Rinonapoli G, Rollo G, Meccariello L, Falzarano G, et al. Tubular vs Profile Plate in Peroneal or Bimalleolar Fractures: is There a Real Difference in Skin Complication? A Retrospective Study in Three Level I Trauma Center. Med Arch. août 2017;71(4):265-9.

35. Lynde MJ, Sautter T, Hamilton GA, Schuberth JM. Complications after open reduction and internal fixation of ankle fractures in the elderly. Foot Ankle Surg. juin 2012;18(2):103-7.

36. Moriarity A, Ellanti P, Mohan K, Fhoghlu CN, Fenelon C, McKenna J. A comparison of complication rates between locking and non-locking plates in distal fibular fractures. Orthop Traumatol Surg Res. juin 2018;104(4):503-6.

37. Moss LK, Kim-Orden MH, Ravinsky R, Hoshino CM, Zinar DM, Gold SM. Implant Failure Rates and Cost Analysis of Contoured Locking Versus Conventional Plate Fixation of Distal Fibula Fractures. Orthopedics. 1 nov 2017;40(6):e1024-9. 
38. Naumann MG, Sigurdsen U, Utvåg SE, Stavem K. Incidence and risk factors for removal of an internal fixation following surgery for ankle fracture: A retrospective cohort study of 997 patients. Injury. août 2016;47(8):1783-8. 

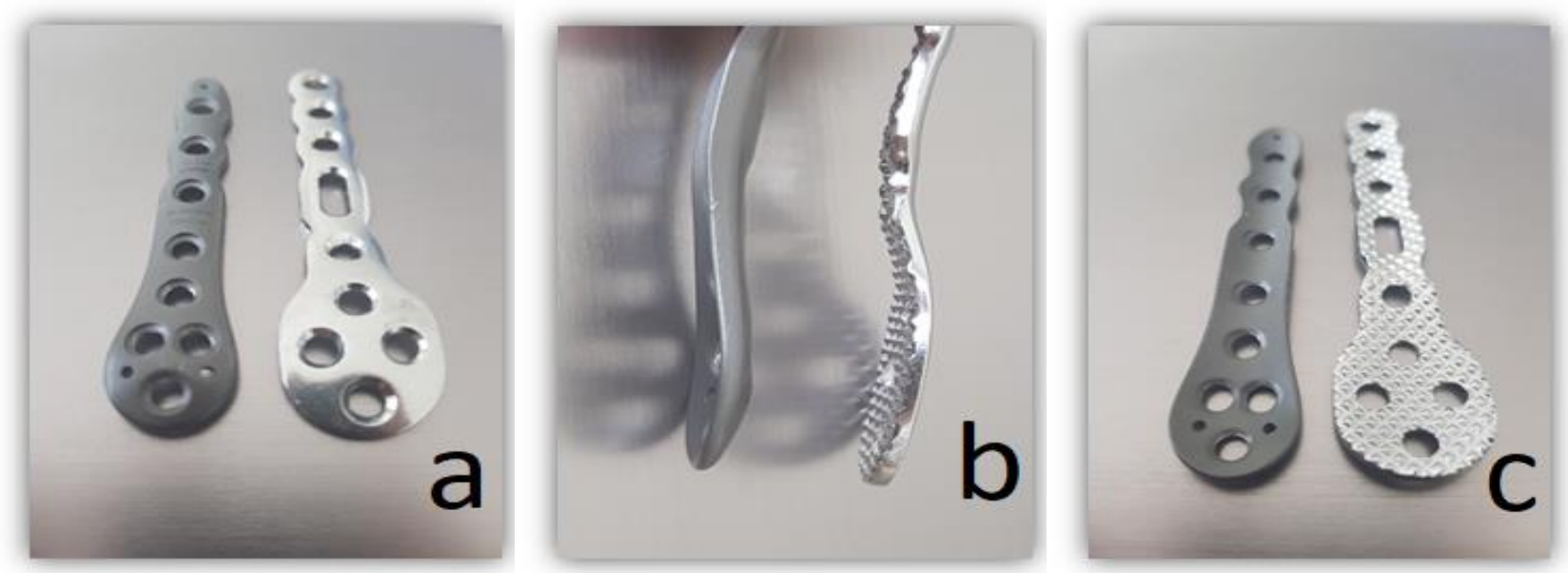

Figure 1 : a) lateral surface, b) length, c) medial or deep surface of the VariAx ${ }^{\mathrm{TM}}$ plate on the left and the Vives ${ }^{\mathrm{TM}}$ on the right

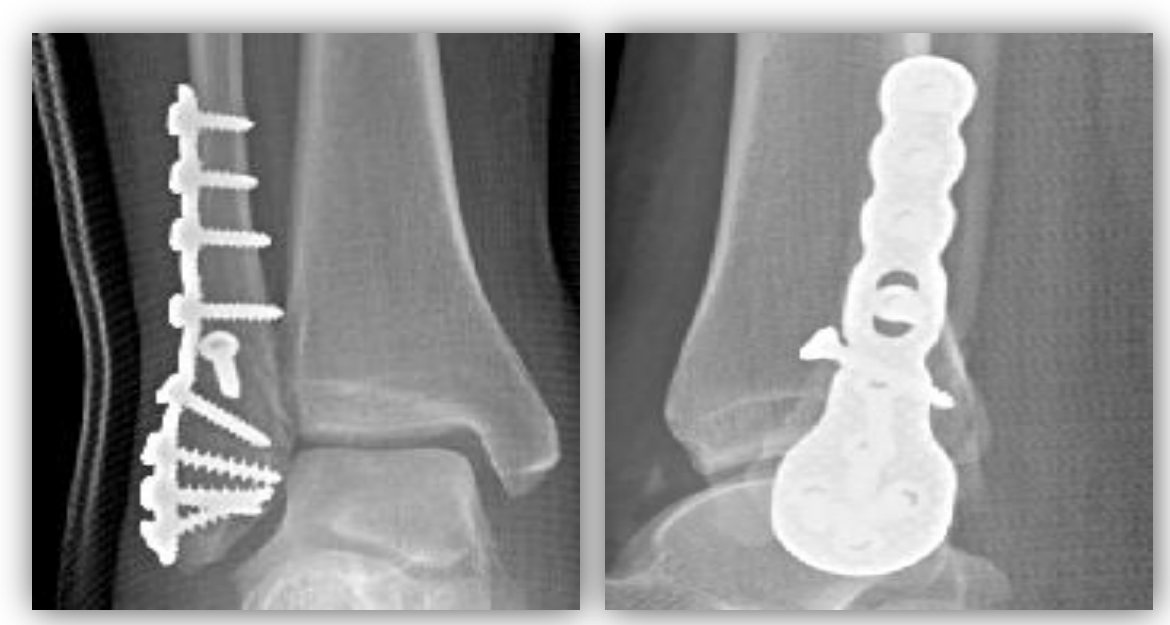

Figure 2: Anterior posterior and lateral view of a VariAx ${ }^{\mathrm{TM}}$ plate osteosynthesis
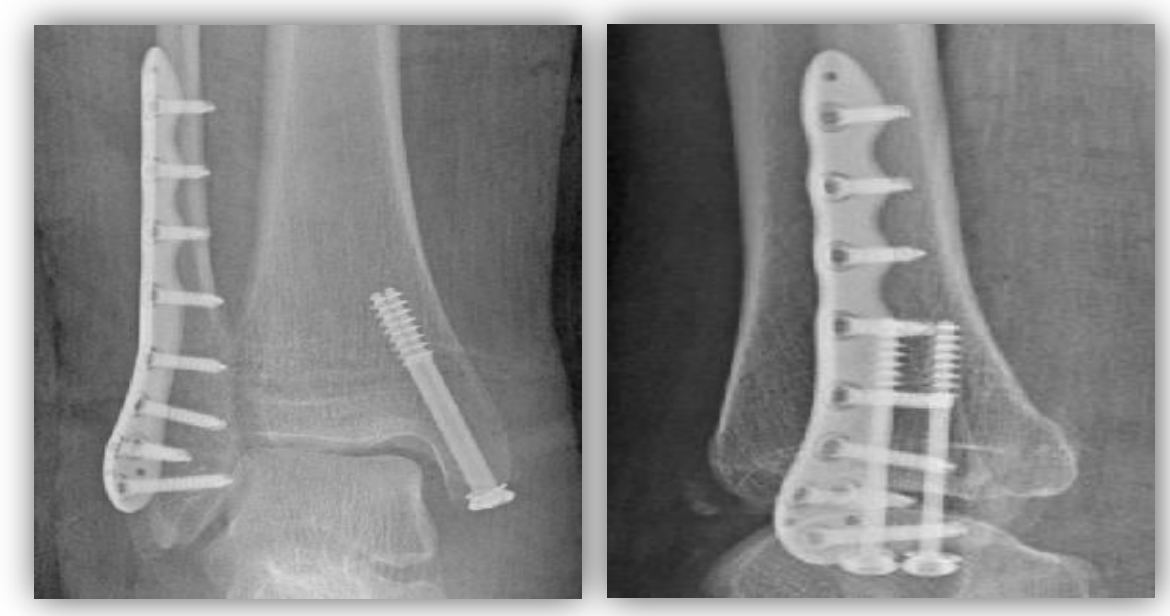

Figure 3: Anterior posterior and lateral view of a Vives TM plate osteosynthesis 


\section{8 ankle fractures}

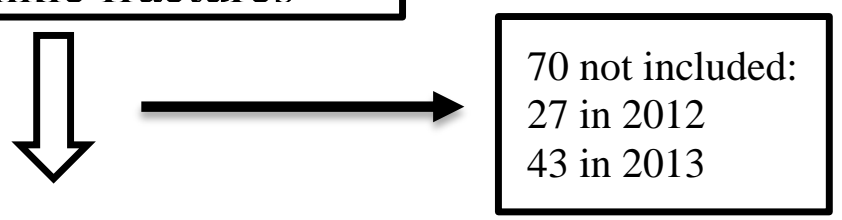

8 open fractures

26 one-third tubular NLP

2 different LP

34 other types of osteosynthesis

128 distal fibulas fixed with lateral plate

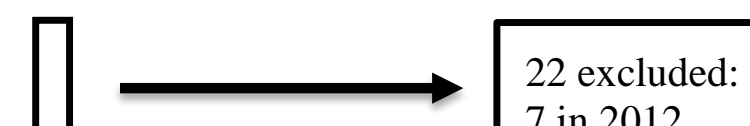

7 in 2012

15 in 2013
16 lost from sight 6 patients achieved their follow-up in another institute

\section{6 included}

\section{5 analyzed}
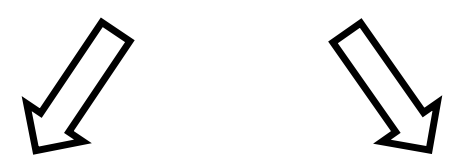

42 NLP (Vives ${ }^{\mathrm{TM}}$ Stryker $\left.^{\circledR}\right)$

63 LP (VariAx ${ }^{\mathrm{TM}}$ Stryker ${ }^{\circledR}$ ) 
Table 1: Population and surgical characteristics

${ }^{a}$ Pearson's Chi-squared test $/{ }^{b}$ Welch Two Sample t-test (Student) $/{ }^{c}$ Fisher's Exact Test

* Means + /- standard deviation and range

\begin{tabular}{|c|c|c|c|c|c|}
\hline & & Total & NLP & $\mathbf{L P}$ & p-value \\
\hline Patients (n) & & 105 & 42 & 63 & \\
\hline \multirow[t]{2}{*}{ Gender (\%) } & Male & $42(40)$ & $18(42,86)$ & $24(38,1)$ & \multirow[t]{2}{*}{$0,625^{\mathrm{a}}$} \\
\hline & Female & $63(60)$ & $24(57,14)$ & $39(61,9)$ & \\
\hline \multicolumn{2}{|l|}{ Age $*^{*}$} & $\begin{array}{c}50,4+/-17,2 \\
{[17 ; 84]}\end{array}$ & $\begin{array}{c}51,8+/-18,7 \\
{[20-84]}\end{array}$ & $\begin{array}{c}49,4+/-16,2 \\
{[17-82]}\end{array}$ & $0,486^{b}$ \\
\hline BMI * & & $\begin{array}{l}26,7+/-5,9 \\
{[16,4 ; 46,2]}\end{array}$ & $\begin{array}{c}26,1+/-4,5 \\
{[17,7-42,5]}\end{array}$ & $\begin{array}{c}27,1+/-6,6 \\
{[16,4-46,2]}\end{array}$ & $0,347^{\mathbf{b}}$ \\
\hline \multirow[t]{2}{*}{ Smoking (\%) } & $\mathrm{Y}$ & $44(41,9)$ & $21(50)$ & $23(36,5)$ & \multirow[t]{2}{*}{$0,169^{a}$} \\
\hline & $\mathrm{N}$ & $61(58,1)$ & $21(50)$ & $40(63,5)$ & \\
\hline \multirow{2}{*}{ Alcohol (\%) } & Y & $19(18,09)$ & $9(21,43)$ & $10(15,88)$ & \multirow[t]{2}{*}{$0,468^{a}$} \\
\hline & $\mathrm{N}$ & $86(81,91)$ & $33(78,57)$ & $53(84,12)$ & \\
\hline \multirow[t]{2}{*}{ Diabetes mellitus (\%) } & $\mathrm{Y}$ & $10(9,52)$ & $4(9,52)$ & $6(9,52)$ & \multirow[t]{2}{*}{$1^{\mathbf{c}}$} \\
\hline & $\mathrm{N}$ & $95(90,48)$ & $38(90,48)$ & $57(90,48)$ & \\
\hline \multirow{2}{*}{$\begin{array}{c}\text { Peripheral arterial } \\
\text { disease }(\%)\end{array}$} & $\mathrm{Y}$ & $2(1,9)$ & 0 & $2(3,18)$ & \multirow[t]{2}{*}{$0,515^{\mathrm{c}}$} \\
\hline & $\mathrm{N}$ & $103(98,1)$ & $42(100)$ & $61(96,82)$ & \\
\hline \multirow[t]{2}{*}{ Chronic renal failure (\%) } & $\mathrm{Y}$ & $1(0,95)$ & 0 & $1(1,59)$ & \multirow[t]{2}{*}{$1^{c}$} \\
\hline & $\mathrm{N}$ & $104(99,05)$ & $42(100)$ & $62(98,41)$ & \\
\hline \multirow[t]{2}{*}{ Corticosteroids (\%) } & $\mathrm{Y}$ & $1(0,95)$ & 0 & $1(1,59)$ & \multirow[t]{2}{*}{$1^{\mathbf{c}}$} \\
\hline & $\mathrm{N}$ & $104(99,05)$ & $42(100)$ & $62(98,41)$ & \\
\hline \multirow[t]{4}{*}{ ASA score $(\%)$} & 1 & $32(30,47)$ & $9(21,42)$ & $23(36,5)$ & \multirow[t]{4}{*}{$0,237^{\mathbf{c}}$} \\
\hline & 2 & $65(61,9)$ & $29(69,05)$ & $36(57,14)$ & \\
\hline & 3 & $8(7,62)$ & $4(9,52)$ & $4(6,34)$ & \\
\hline & 4 & 0 & 0 & 0 & \\
\hline \multirow[t]{2}{*}{ Side } & $\mathrm{Y}$ & $52(49,52)$ & $23(54,8)$ & $29(46)$ & \multirow[t]{2}{*}{$0,38^{\mathrm{a}}$} \\
\hline & G & $53(50,48)$ & $19(45,2)$ & $34(54)$ & \\
\hline \multirow[t]{2}{*}{ Dislocation (\%) } & $\mathrm{Y}$ & $31(29,52)$ & $14(33,33)$ & $17(26,98)$ & \multirow[t]{2}{*}{$0,484^{\mathrm{a}}$} \\
\hline & $\mathrm{N}$ & $74(70,48)$ & $28(66,67)$ & $46(73,01)$ & \\
\hline \multirow[t]{2}{*}{ Skin Blisters (\%) } & $\mathrm{Y}$ & $15(14,29)$ & $8(19,05)$ & $7(11,12)$ & \multirow[t]{2}{*}{$0,254^{\mathrm{a}}$} \\
\hline & $\mathrm{N}$ & $90(85,71)$ & $34(80,95)$ & $56(88,88)$ & \\
\hline Fracture Type: AO & $44-\mathrm{A} 1$ & $2(1,9)$ & $2(4,76)$ & 0 & $0,011^{c}$ \\
\hline Classification (\%) & $44-\mathrm{A} 2$ & 0 & 0 & 0 & \\
\hline & $44-\mathrm{A} 3$ & 0 & 0 & 0 & \\
\hline & 44-B1 & $17(16,19)$ & $2(4,76)$ & $15(23,8)$ & \\
\hline & 44-B2 & $70(66,67)$ & $33(78,57)$ & $37(58,73)$ & $0,024^{a}$ \\
\hline & 44-B3 & $15(14,28)$ & $5(11,9)$ & $10(15,87)$ & \\
\hline & $44-\mathrm{C} 1$ & 0 & 0 & 0 & \\
\hline & $44-C 2$ & $1(0,95)$ & 0 & $1(1,59)$ & \\
\hline & $44-\mathrm{C} 3$ & 0 & 0 & 0 & \\
\hline Lag Screw (\%) & $\mathrm{Y}$ & $58(55,24)$ & $17(40,48)$ & $41(65,08)$ & $0,012^{a}$ \\
\hline & $\mathrm{N}$ & $47(44,76)$ & $25(59,52)$ & $22(34,92)$ & \\
\hline Operation time (min) & & $\begin{array}{c}61,92+/-19,45 \\
{[35 ; 120]}\end{array}$ & $\begin{array}{c}60,23+/-16,99 \\
{[40 ; 110]}\end{array}$ & $\begin{array}{c}63,04+/-20,99 \\
{[35 ; 120]}\end{array}$ & $0,452^{b}$ \\
\hline
\end{tabular}


Table 2: Radiographic bone union at 6 and 12 weeks postoperatively No: Persistency of a visible fracture line on one or more radiographic views Yes: complete disappearance of the fracture line on both anterior posterior and lateral views

${ }^{a}$ Pearson's Chi-squared test $/{ }^{b}$ Fisher's Exact Test

\begin{tabular}{llcccc}
\hline & & Total cohort & NLP & LP & p-value \\
\hline Bone union at 6 weeks & No & $18(42,86)$ & $6(14,29)$ & $12(19)$ & $0,525^{\mathbf{a}}$ \\
& Yes & $24(57,14)$ & $36(85,71)$ & $51(81)$ & \\
\hline Bone union at 12 weeks & No & $3(4,76)$ & $1(2,38)$ & $2(3,17)$ & $1^{\mathbf{b}}$ \\
& Yes & $60(95,24)$ & $41(97,62)$ & $61(96,83)$ & \\
\hline
\end{tabular}

Table 3: Simple linear analysis of bone union at 6 and 12 weeks, and of hardware removal rate

${ }^{a}$ Pearson's Chi-squared test $/{ }^{b}$ Welch Two Sample t-test (Student) $/{ }^{c}$ Fisher's Exact Test

\begin{tabular}{|c|c|c|c|}
\hline Variables & 6 weeks & 12 weeks & Hardware removal \\
\hline Plate (NLP/LP) & $0,525^{\mathrm{a}}$ & $1,000^{\mathrm{c}}$ & $0,183^{\mathrm{a}}$ \\
\hline Age & $0,264^{b}$ & $0,811^{b}$ & $<0,001^{b}$ \\
\hline Gender & $0,916^{\mathrm{a}}$ & $0,811^{\mathrm{a}}$ & $0,622^{\mathrm{a}}$ \\
\hline BMI & $0,249^{b}$ & $0,763^{b}$ & $0,776^{\mathrm{b}}$ \\
\hline Smoking & $0,810^{\mathrm{a}}$ & $1,000^{\mathrm{c}}$ & $0,520^{c}$ \\
\hline Alcohol & $1,000^{\mathrm{c}}$ & $0,454^{\mathrm{c}}$ & $0,603^{\mathrm{a}}$ \\
\hline Diabetes Mellitus & $1,000^{\mathrm{c}}$ & $1,000^{\mathrm{c}}$ & $0,490^{c}$ \\
\hline Peripheral arterial disease & $1,000^{\mathrm{c}}$ & $1,000^{\mathrm{c}}$ & $1,000^{\mathrm{c}}$ \\
\hline Chronic renal failure & $1,000^{\mathrm{c}}$ & $1,000^{c}$ & $1,000^{c}$ \\
\hline Corticosteroids & $1,000^{\mathrm{c}}$ & $1,000^{\mathrm{c}}$ & $1,000^{c}$ \\
\hline ASA Score & $0,242^{c}$ & $0,645^{\mathrm{c}}$ & $0,093^{c}$ \\
\hline Sub-type 44-B (B1, B2 et B3) & $0,045^{c}$ & $0,442^{\mathrm{c}}$ & $0,019^{c}$ \\
\hline Skin Blisters & $0,284^{\mathrm{c}}$ & $\mathbf{0 , 0 5 3}{ }^{\mathrm{c}}$ & $0,941^{\mathrm{a}}$ \\
\hline Lag screw & $0,623^{\mathrm{a}}$ & $0,586^{\mathrm{c}}$ & $0,223^{\mathrm{a}}$ \\
\hline Wound complications & $1,000^{\mathrm{c}}$ & $0,308^{c}$ & $\mathbf{0 , 0 3 8}^{\mathrm{c}}$ \\
\hline
\end{tabular}

Table 4: multiple linear regression analysis at 6 weeks

\begin{tabular}{lcc}
\hline Variables & OR [IC95\%] & p-value \\
\hline LP $($ ref $=$ NLP) & $0,899[0,263 ; 2,939]$ & 0,86 \\
\hline Age & $1,016[0,98 ; 1,054]$ & 0,384 \\
\hline Male Gender (ref =female) & $1,253[0,357 ; 4,758]$ & 0,729 \\
\hline AO 44-B2 $($ ref $=$ 44-B1) & $0,743[0,097 ; 3,819]$ & 0,741 \\
\hline AO 44-B3 $($ ref=44-B1) & $0,186[0,022 ; 1,107]$ & 0,082 \\
\hline AO 44-B1 $($ ref = 44-B2) & $1,345[0,262 ; 10,263]$ & 0,74 \\
\hline AO 44-B3 (ref = 44-B2) & $\mathbf{0 , 2 5}[\mathbf{0 , 0 6 9 ; 0 , 9 3 6 ]}$ & $\mathbf{0 , 0 3 5}$ \\
\hline
\end{tabular}

Table 5: multiple linear regression analysis at 12 weeks

\begin{tabular}{lcc}
\hline Variables & OR [IC95\%] & p-value \\
\hline LP $($ ref = NLP) & $0,538[0,021 ; 7,041]$ & 0,644 \\
\hline Age & $1,012[0,927 ; 1,108]$ & 0,788 \\
\hline Male Gender (ref =female) & $1,736[0,091 ; 60,099]$ & 0,72 \\
\hline Skin Blisters (ref= NO) & $\mathbf{0 , 0 6 6}[\mathbf{0 , 0 0 3 ; 0 , 7 6 2}]$ & $\mathbf{0 , 0 3 4}$ \\
\hline
\end{tabular}


Table 6: General and wound complications

Wound complications: superficial or minor complications = delayed wound healing and wound secondary dehiscence / deep or major infectious complications = dehiscence after infection Other complications: Complex regional pain syndrome (CRPS), synostosis, Deep vein thrombosis (DVT), Heparin-induced thrombocytopenia (HIT), tibialis posterior tendinopathy (TPT), post-operative ankle stiffness

${ }^{a}$ Pearson's Chi-squared test $/{ }^{b}$ Welch Two Sample t-test (Student)

\begin{tabular}{cccccc}
\hline & & Total cohort & NLP & LP & p-value \\
\hline $\begin{array}{c}\text { Wound } \\
\text { complications (\%) }\end{array}$ & $12(11,42)$ & $5(11,9)$ & $7(11,12)$ & $0,9^{\mathbf{a}}$ \\
\hline Minor (\%) & & $6(6,67)$ & $1(2,38)$ & $5(7,94)$ & $0,398^{\mathrm{b}}$ \\
\hline Major (\%) & & $6(4,76)$ & $4(9,52)$ & $2(3,17)$ & $0,154^{\mathrm{b}}$ \\
\hline Other & CRPS & $9(8,57)$ & $4(9,52)$ & $5(7,93)$ & $1^{\mathbf{c}}$ \\
complications (\%) & Synostosis & $5(4,76)$ & $3(7,14)$ & $2(3,17)$ & \\
& DVT & $1(0,95)$ & $1(2,38)$ & 0 & \\
& HIT & $1(0,95)$ & $1(2,38)$ & 0 & \\
TPT & $1(0,95)$ & 0 & $1(1,58)$ & \\
complications $(\%)$ & Stiffness & $1(0,95)$ & $1(2,38)$ & 0 & \\
\hline $\begin{array}{c}\text { Total All } \\
\text { Complications }(\%)\end{array}$ & & $18(17,14)$ & $10(23,8)$ & $8(12,69)$ & $0,138^{\mathbf{a}}$ \\
\hline
\end{tabular}

Table 7: Hardware removal rate

HRR: Hardware removal rate

${ }^{a}$ Pearson's Chi-squared test $/{ }^{\mathrm{b}}$ Welch Two Sample t-test (Student)

* Means $+/$ - standard deviation and range

\begin{tabular}{ccccc}
\hline & Total cohort & NLP & LP & p-value \\
\hline General HRR (\%) & $38(36,19)$ & $13(30,95)$ & $25(39,68)$ & $0,361^{\mathbf{a}}$ \\
\hline Time (Month)* & $14,4+/-7,8$ & $10,2+/-5,43$ & $16,5+/-8,1$ & $\mathbf{0 , 0 0 7}^{\mathbf{b}}$ \\
& {$[2 ; 38]$} & {$[2 ; 18]$} & {$[2 ; 38]$} & \\
\hline HRR Without Infection (\%) $^{*}$ & $33(31,42)$ & $9(21,42)$ & $24(38,09)$ & $0,071^{\mathbf{a}}$ \\
\hline Time (Month)* & $16+/-6,8$ & $13,5+/-2,5$ & $17,2+/-7,7$ & $\mathbf{0 , 0 4 4}^{\mathbf{b}}$ \\
& {$[8 ; 38]$} & {$[10 ; 18]$} & {$[8 ; 38]$} & \\
\hline
\end{tabular}

Table 8: multiple linear regression analysis of hardware removal

\begin{tabular}{ccc}
\hline Variables & OR $[$ IC95\% $]$ & p-value \\
LP $($ ref $=$ NLP) & $2,238[0,721 ; 7,538]$ & 0,173 \\
\hline Age & $\mathbf{0 , 9 4}[\mathbf{0 , 8 9 9 ; 0 , 9 7 8}]$ & $\mathbf{0 , 0 0 4}$ \\
\hline Gender Male $($ ref $=$ Female $)$ & $0,778[0,23 ; 2,51]$ & 0,677 \\
\hline AO 44-B2 $($ ref=44-B1) & $2,009[0,508 ; 9,076]$ & 0,337 \\
\hline AO 44-B3 $($ ref=44-B1) & $\mathbf{8 , 5 6 8}[\mathbf{1 , 4 7 8 ; 5 9 , 8 1 7}]$ & $\mathbf{0 , 0 2 1}$ \\
\hline AO 44-B1 (ref=44-B2) & $0,462[0,104 ; 1,784]$ & 0,28 \\
\hline AO 44-B3 (ref=44-B2) & $\mathbf{4 , 0 7 5}[\mathbf{1 , 0 2 1} ; \mathbf{1 7 , 4 5 5}]$ & $\mathbf{0 , 0 4 8}$ \\
\hline Wound Complications $($ ref=NO) & $4,784[0,741 ; 40,789]$ & 0,11 \\
\hline
\end{tabular}


Table 9: Cost evaluation

\begin{tabular}{lccc}
\hline & NLP & LP & Difference \\
\hline Plate cost (whatever the length) & $148,5 €$ & $168 €$ & $19,5 €$ \\
\hline Proximal screw cost (CORTICAL) & $6 €$ & $6 €$ & 0 \\
\hline $\begin{array}{l}\text { Distal screw cost (CANCELLOUS vs. } \\
\text { LOCKING) }\end{array}$ & $6 €$ & $60 €$ & $54 €$ \\
\hline $\begin{array}{l}\text { Price of 4 distal screws within the periarticular } \\
\text { part of the plate }\end{array}$ & $24 €$ & $240 €$ & $216 €$ \\
\hline $\begin{array}{l}\text { Construct cost without Proximal screws } \\
\text { Pons }\end{array}$ & $172,5 €$ & $408 €$ & $\mathbf{2 3 5 , 5}$ \\
\hline
\end{tabular}

